\title{
Inhibition of SOX4 induces melanoma cell apoptosis via downregulation of NF-кB p65 signaling
}

\author{
QIONG CHENG ${ }^{*}$, JUAN DU $^{2 *}$, LIN XIE $^{2}, \mathrm{XIAO} \mathrm{LIU}^{2}, \mathrm{ZHENG} \mathrm{LI}^{2}$, \\ FUGUO ZUO ${ }^{1}$, JINFENG $\mathrm{WU}^{2}$ and JINHUA XU ${ }^{2}$ \\ ${ }^{1}$ Department of Dermatology, East Hospital, Tongji University School of Medicine, Shanghai 200120; \\ ${ }^{2}$ Department of Dermatology, Huashan Hospital, Fudan University, Shanghai 200040, P.R. China
}

Received October 1, 2017; Accepted March 30, 2018

DOI: $10.3892 /$ or.2018.6443

\begin{abstract}
SOX4 (SRY Box 4) has attracted attention due to its important effects on cell growth, proliferation and apoptosis, among other cellular processes. However, the role of SOX4 in melanoma cell apoptosis remains unclear. In the present study, we investigated whether inhibition of SOX4 induces melanoma cell apoptosis, and explored the possible mechanism involving the NF- $\kappa \mathrm{B}$ signaling pathway. SOX4 was knocked down using a lentivirus in melanoma A2058 and SK-MEL-5 cell lines. Cell proliferation was measured by MTT assay. Apoptosis was determined by flow cytometry. Western blotting was performed to detect the protein levels of SOX4, p65 and apoptosis-related proteins, such as PARP, Bcl-2, Bax and survivin. Quantitative real-time PCR (qRT-PCR) was used to examine the mRNA levels of SOX4 and p65. To determine whether SOX4 is able to bind to the promoter of p65, a CHIP-PCR assay was performed. Our data demonstrated that SOX4 knockdown significantly induced apoptosis in melanoma cells, which was accompanied by increases in cleaved PARP and Bax, and decreases in Bcl-2 and survivin. The expression of p65 was also decreased in SOX4-knockdown melanoma cells. The CHIP-PCR assay indicated that SOX4 was able to bind to the promoter region of p65. We also observed that apoptosis in SOX4-knockdown and p65-overexpressing A2058 cells was much lower than that in SOX4-knockdown alone cells. This revealed that the overexpression of p65 partially reversed SOX4 downregulation-induced apoptosis. In conclusion, our results demonstrated that inhibition of SOX4 markedly induced melanoma cell apoptosis via downregulation of the
\end{abstract}

Correspondence to: Dr Jinhua Xu or Dr Jinfeng Wu, Department of Dermatology, Huashan Hospital, Fudan University, 12 Middle Urumqi Road, Shanghai 200040, P.R. China

E-mail: xjhhsyy@163.com

E-mail: wujinfeng21@163.com

${ }^{*}$ Contributed equally

Key words: melanoma, $\mathrm{SOX} 4, \mathrm{NF}-\kappa \mathrm{B}$, apoptosis
$\mathrm{NF}-\kappa \mathrm{B}$ signaling pathway, which thus may be a novel approach for the treatment of melanoma.

\section{Introduction}

SOX4 (SRY Box 4) is a 47-kDa protein and contains a conserved signature sequence in the high-mobility group (HMG). SOX4 is highly expressed in almost all types of cancer in humans, and plays an important role in the development of tumors (1). Recent studies have uncovered the key functions of the SOX4 gene as a regulator of cancer cell proliferation, apoptosis, invasion and metastasis.

SOX4 is considered to be a tumor-suppressor gene or an oncogene in different types of tumors. For example, SOX4 inhibits the cell proliferation of polymorphous glioblastoma (GBM) (2). However, high expression of SOX4 in nasopharyngeal carcinoma promotes tumor growth and metastasis (3). Whether SOX4 promotes apoptosis or represses apoptosis in different tumors remains a controversial question. Liu et al revealed that silencing of SOX4 by small interfering RNA transfection induced apoptosis in prostate cancer cells (4). Yoon et al found that SOX4 knockdown (KO) induced apoptosis by activating caspase- 3 and caspase-7 in head and neck squamous cell carcinoma (HNSCC) cells (5). Hur et al reported that SOX4 overexpression led to a significant suppression of p53-induced Bax expression, and subsequent repression of p53-mediated apoptosis induced by $\gamma$-irradiation (6). Pramoonjago et al discovered that SOX4 knockdown resulted in the apoptosis of adenoid cystic carcinoma (ACC) cells (7) and Bilir et al also reported that SOX4 knockdown enhanced the effects of a wnt pathway inhibitor (iCRT-3) on apoptosis in breast cancer cells (8). Other researchers have reported the opposite findings regarding the role of SOX4 in apoptosis. Pan et al revealed that SOX4 promoted cell cycle arrest and apoptosis in human lung non-small cell carcinoma H460 cells (9). Aaboe et al confirmed that SOX4 strongly impaired bladder carcinoma cell viability and promoted apoptosis (10). Li et al revealed that SOX4 was more highly expressed in primarystage (AJCC I and II) than in advanced-stage (AJCC III and IV) melanoma cases (11). Jafarnejad et al reported that SOX4 was underexpressed in metastatic melanoma compared with dysplastic nevi and primary melanoma; furthermore, knockdown of SOX4 enhanced melanoma cell invasion (12). 
Table I. PCR primer data.

\begin{tabular}{llc}
\hline Gene name & \multicolumn{1}{c}{ Forward primer } & \multicolumn{1}{c}{ Reverse primer } \\
\hline SOX4 & ACAGCGACAAGATCCCTTTC & CGGACTTCACCTTCTTCCTG \\
P65 & AGCACAGATACCACCAAGACC & CGGCAGTCCTTTCCTACAAG \\
\hline
\end{tabular}

However, the role of SOX4 in the apoptosis of melanoma cells remains unknown.

$\mathrm{NF}-\kappa \mathrm{B}$ is a classical signaling pathway that is involved in the survival, proliferation and apoptosis of tumor cells. Watanabe et al revealed that inhibition of the expression and/ or activity of NF- $\mathrm{KB}$ induced apoptosis in melanoma cells (13). In this study, the role of SOX4 in the apoptosis of melanoma A2058 and SK-MEL-5 cells was investigated, and the underlying mechanisms were determined. We demonstrated that inhibition of SOX4 markedly induced melanoma cell apoptosis via downregulation of the NF- $\kappa \mathrm{B}$ signaling pathway, thus, indicating a novel target for melanoma treatment.

\section{Materials and methods}

Cell culture and lentiviral transfection. The human melanoma A2058 and SK-MEL-5 cell lines were purchased from the American Type Culture Collection (ATCC; Manassas, VA, USA) and were cultured in Dulbecco's modified Eagle's medium (DMEM; Invitrogen; Thermo Fisher Scientific, Carlsbad, CA, USA), supplemented with $1 \%$ penicillin/streptomycin (Sigma-Aldrtich; Merck KGaA, Darmstand, Germany) and $10 \%$ fetal bovine serum (FBS; Thermo Fisher Scientific) at $37^{\circ} \mathrm{C}$. The melanoma cells $\left(8 \times 10^{4} /\right.$ well) were plated into 6 -well plates and incubated overnight. When the melanoma cells had reached $\sim 70 \%$ confluence, they were infected with SOX4 shRNA (Shanghai GeneChem Co., Ltd., Shanghai, China) and/or p65-overexpressing lentivirus (Shanghai GeneChem Co., Ltd.) in FBS-free medium containing $6 \mu \mathrm{g} / \mathrm{ml}$ Polybrene (Sigma-Aldrtich; Merck KGaA). We used blank vector lentivirus as the control. Twenty-four hours later, the FBS-free medium was replaced with $10 \%$ FBS culture medium. SOX4 and p65 expression in cells was confirmed by western blot analysis and a real-time PCR assay $72 \mathrm{~h}$ after lentiviral infection.

MTT assay. Cells $\left(5 \times 10^{3}\right)$ were seeded in 96-well plates. At 24,48 or $72 \mathrm{~h}$ post-transfection, $20 \mu 1$ MTT solution $(5 \mathrm{mg} / \mathrm{ml})$ was added to each well and incubated for $4 \mathrm{~h}$. The medium was subsequently removed and $150 \mu \mathrm{l}$ dimethyl sulfoxide (DMSO) was added. The optical density (OD) was detected at $600 \mathrm{~nm}$ with a microplate spectrophotometer (BD Biosciences, San Jose, CA, USA).

Western blot assay. A2058 and SK-MEL-5 cells were lysed in RIPA buffer (Beyotime Institute of Biotechnology, Haimen, China) for total protein extraction. The cells were lysed on ice for $15 \mathrm{~min}$, after $12,000 \mathrm{rpm}$ centrifugation for $10 \mathrm{~min}$. The proteins in the supernatant were extracted. We carried out nuclear protein extraction, according to the manufacturer's protocol (Beyotime Institute of Biotechnology). The samples were separated by $12 \%$ SDS-PAGE, then transferred onto polyvinylidene fluoride (PVDF) membranes. After blocking of the membranes in 5\% skimmed milk, the membranes were incubated with specific antibodies against SOX4 (1:100 dilution; cat. no. ab85204; Abcam, Cambridge, UK), Bcl-2 (1:1,000 dilution; cat. no. ab32124; Abcam), Bax (1:1,000 dilution; cat. no. ab32503), survivin (1:5,000 dilution; cat. no. ab76424; Abcam), p65 (1:1,000 dilution, cat. no. 3039; Cell Signaling Technology, Beverly, MA, USA) and PARP (1:1,000 dilution; cat. no. 9542; Cell Signaling Technology). An ECL detection system was used to detect the protein bands (Amersham Pharmacia Biotechnology, Tokyo, Japan).

Apoptosis assay. Apoptosis was determined based on Annexin V/7AAD staining using an Apoptosis Detection kit (BD Biosciences, San Diego, CA, USA), according to the manufacturer's instructions. Cells were harvested at $72 \mathrm{~h}$ post-transfection, and $2 \times 10^{4}$ cells were collected and suspended in $100 \mu \mathrm{l} 1 \mathrm{X}$ binding buffer, mixed with $5 \mu \mathrm{l}$ Annexin V-PE and $5 \mu \mathrm{l}$ 7AAD, in darkness for $20 \mathrm{~min}$, and then $400 \mu \mathrm{l}$ of $1 \mathrm{X}$ binding buffer was added to stop the staining reaction. Data were acquired using a FACSCalibur ${ }^{\mathrm{TM}}$ (BD Biosciences). Apoptosis was analyzed using FlowJo software v6.0 (Tree Star, Inc., Ashland, OR, USA).

RNA extraction and real-time PCR assay. Total RNA was extracted from melanoma cells using TRIzol reagent (Invitrogen; Thermo Fisher Scientific). Real-time PCR was performed using a SYBR ${ }^{\circledR}$ Premix Dimer Eraser ${ }^{\mathrm{TM}}$ kit (Takara Biotechnology, Co., Ltd., Dalian, China) in a $25-\mu 1$ reaction system. Denaturation was performed at $95^{\circ} \mathrm{C}$ for $30 \mathrm{sec}$, annealing at $60^{\circ} \mathrm{C}$ for $30 \mathrm{sec}$, and elongation at $72^{\circ} \mathrm{C}$ for $30 \mathrm{sec}$ over 39 cycles. An ABI Prism 7900HT fast RT-PCR system (Applied Biosystems; Thermo Fisher Scientific) was used to perform the real-time PCR assay. The primers were designed as shown in Table I.

Chromatin immunoprecipitation (CHIP). The CHIP assay was performed according to the manufacturer's protocol (Millipore, Billerica, MA, USA). At $72 \mathrm{~h}$ after lentiviral infection, the A2058 cells were cross-linked using $1 \%$ formaldehyde (Sigma-Aldrich; Merck KGaA) for $10 \mathrm{~min}$ at room temperature and stopped with glycine buffer, followed by sonication. DNA was sheared to fragments of 200-1,000 bp in length. Anti-SOX4 antibody was added at $4^{\circ} \mathrm{C}$ overnight with rotation and $\operatorname{IgG}$ was used as a control. The immunoprecipitated DNA fragments were detected on $2 \%$ agarose gels and images were analyzed with an LAS 4000 luminescent image analyzer (Fujifilm, Tokyo, Japan). The CHIP primers were generated by Shanghai Sangon Co., Ltd. (Shanghai, China) (Table II). 
A

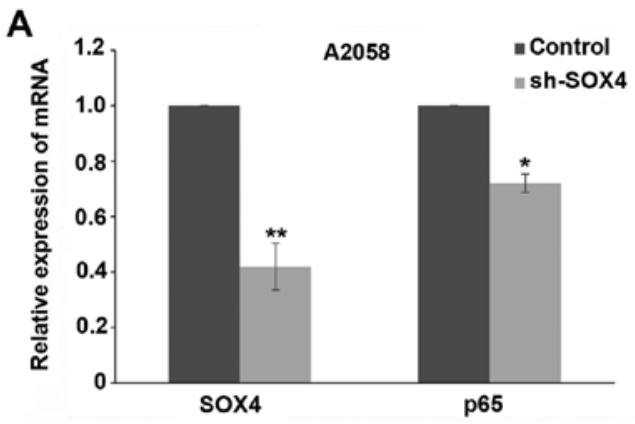

B
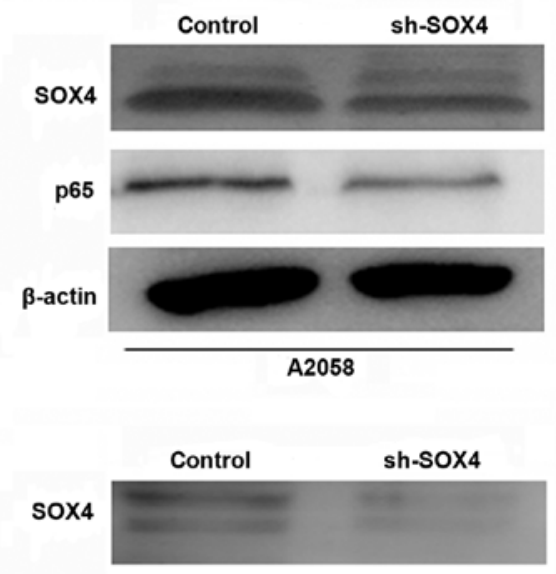

p65

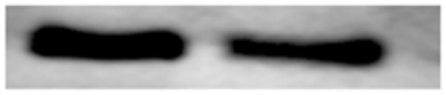

$\beta$-actin

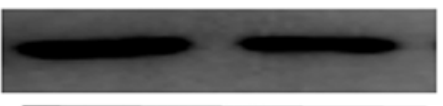

SK-MEL-5

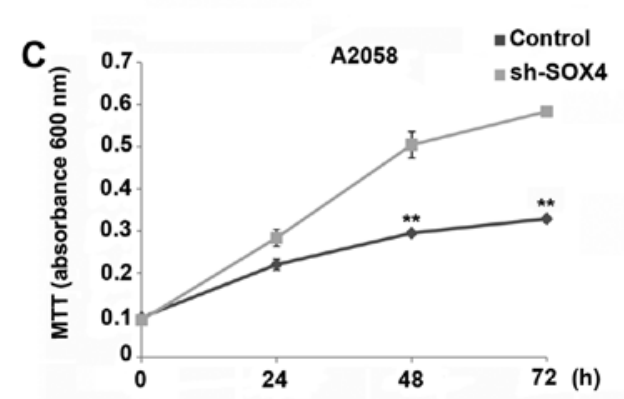

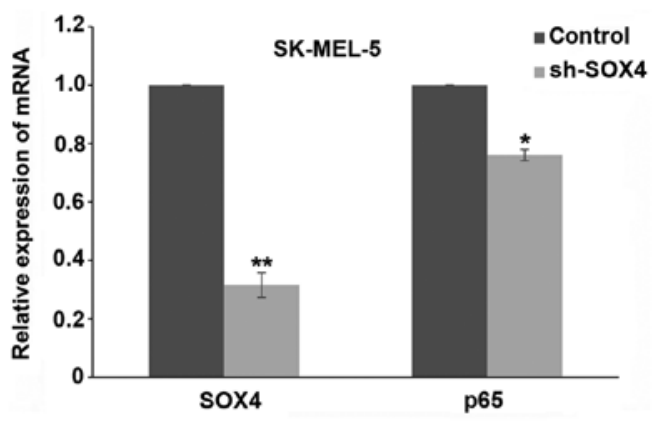
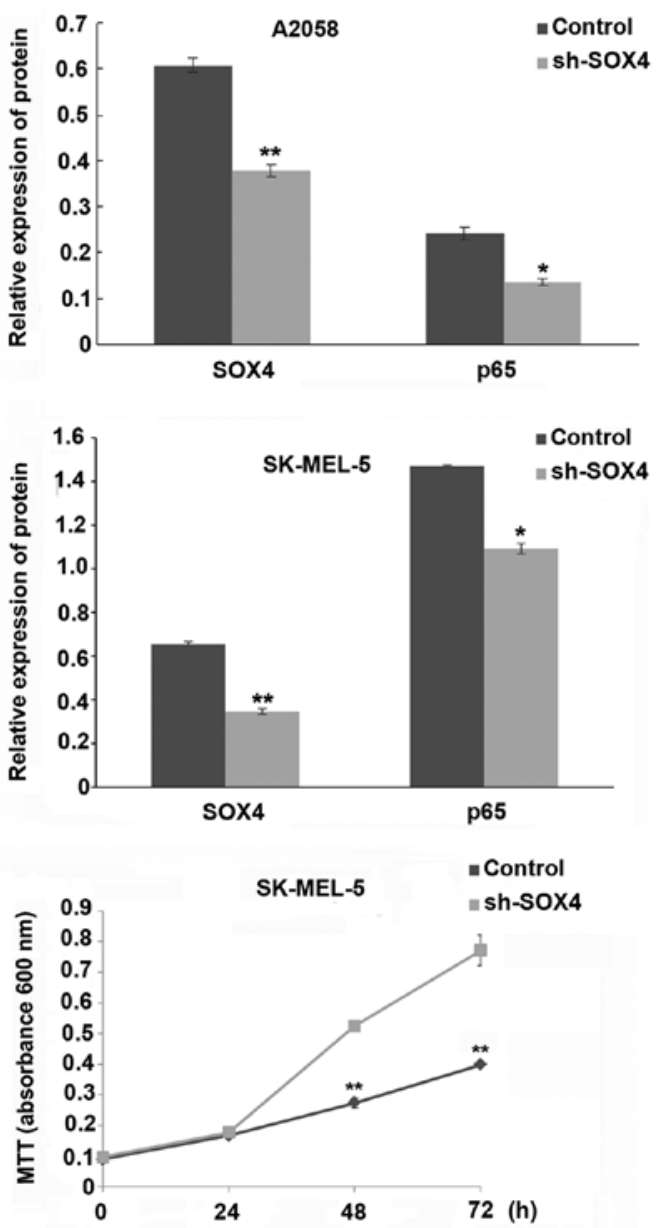

Figure 1. SOX4 downregulation inhibits p65 expression and cell proliferation in melanoma A2058 and SK-MEL-5 cell lines. (A) Real-time PCR assay for SOX4 and p65 mRNA, after SOX4 shRNA lentiviral transfection for $48 \mathrm{~h}$. (B) Western blot analysis of SOX4 and p65 protein, after SOX4 shRNA lentiviral transfection for $72 \mathrm{~h}$. (C) Cell proliferation was determined by MTT assay after SOX4 shRNA lentiviral transfection for 24, 48 and $72 \mathrm{~h}$. Data are shown as the mean \pm standard deviation. Each experiment was performed in triplicate. ${ }^{*} \mathrm{P}<0.05,{ }^{* *} \mathrm{P}<0.01$ indicate statistical significance. sh-SOX4 represents SOX4 shRNA

Table II. p65 PCR primer data.

\begin{tabular}{cll}
\hline p65 & Forward primer & Reverse primer \\
\hline+15 to -104 & cgcgcacttggccccgac & cgcgcctgcgcgct \\
-113 to -202 & acaaagtgagtaatcg & gtcggggccaagtgcgc \\
-1703 to -1810 & cttgagcccaggagtttg & ggcgtgagccaccacgc \\
-1490 to -1603 & ccacttctttacaaa & atctctgctcactgcag \\
-221 to -318 & cctgcgcggggegggc & taggggatttcagggc \\
-1300 to -1405 & atacaatacaatacaata & taacttttaaattaatac \\
-990 to -1100 & gtgctaactctatttcac & gacttttttatttctctga \\
-831 to -931 & catcctcctttggggat & tctgtcatgtgacccc \\
-680 to -780 & acacaggcgggggca & aatcccggagcctcg \\
-350 to -441 & ggtaggacattttaacg & ggccttctgctccgcaga \\
\hline
\end{tabular}

Statistical analysis. All data were obtained from three separate experiments and are presented as the mean \pm standard deviation. Statistical analysis was performed using one-way analysis of variance (ANOVA). When comparing differences between two groups, we used a Student's t-test. Differences were considered to be statistically significant when P-values were $<0.05$.

\section{Results}

SOX4 downregulation inhibits p65 expression and cell proliferation in melanoma cells. As shown in Fig. $1 \mathrm{~A}$ and $\mathrm{B}$, the expression of SOX4 at both the mRNA and protein levels was significantly decreased in SOX4 shRNA-transfected A2058 
A
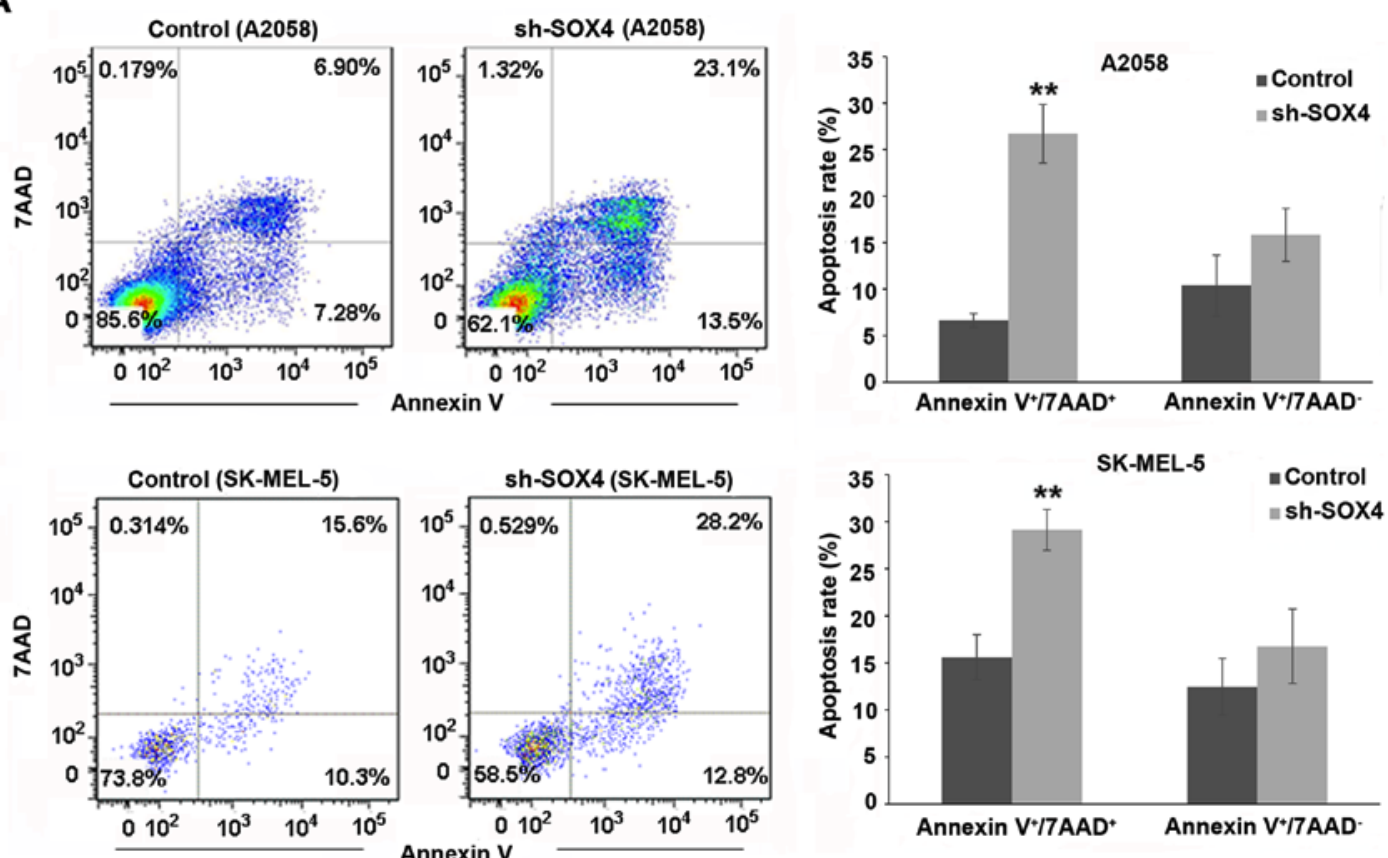

B
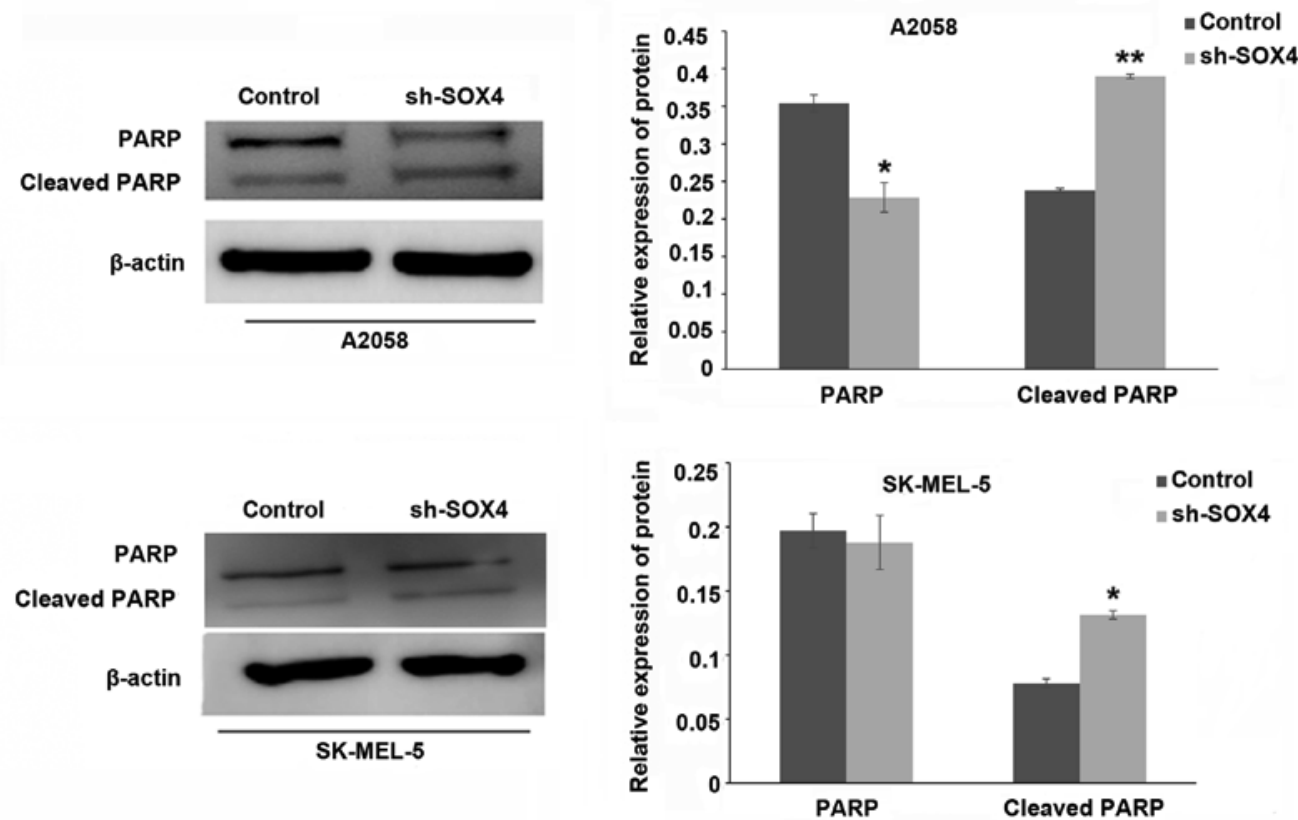

Figure 2. SOX4 downregulation promotes melanoma cell apoptosis. (A) Flow cytometry assay. SOX4 shRNA lentivirus-transfected A2058 and SK-MEL-5 cells were stained with Annexin V/7AAD, and then analyzed by flow cytometry. (B) Western blot analysis of PARP and cleaved PARP protein after SOX4 shRNA lentiviral transfection for $72 \mathrm{~h}$ in A2058 and SK-MEL-5 cells. ${ }^{*} \mathrm{P}<0.05,{ }^{* *} \mathrm{P}<0.01$ indicate statistical significance. sh-SOX4 represents SOX4 shRNA.

and SK-MEL-5 cells, compared to the scrambled shRNA control group $(\mathrm{P}<0.01)$. As demonstrated in Fig. 1C, downregulation of SOX4 markedly inhibited the proliferation of A2058 and SK-MEL-5 cells at 48 or $72 \mathrm{~h}$ post-SOX4 shRNA transfection $(\mathrm{P}<0.01)$. We also observed that SOX4 downregulation inhibited the expression of NF- $\kappa \mathrm{B}$ p65 at both the mRNA and protein levels $(\mathrm{P}<0.05)$ (Fig. 1A and $\mathrm{B})$.

SOX4 downregulation promotes melanoma cell apoptosis. As shown in Fig. 2A, SOX4 downregulation significantly increased the level of apoptosis in the A2058 and SK-MEL-5 cells at $72 \mathrm{~h}$ post-SOX4 shRNA transfection $(\mathrm{P}<0.01)$. The expression of cleaved PARP was increased, while that of pro-PARP was decreased (Fig. $2 \mathrm{~B} ; \mathrm{P}<0.01, \mathrm{P}<0.05$ ).

SOX4 downregulation decreases the expression of Bcl-2 and survivin, and increases the expression of Bax; meanwhile, SOX4 was able to bind to the promoter region of $p 65 . \mathrm{Bcl}-2$ and survivin belong to an anti-apoptotic protein family, while Bax belongs to a pro-apoptotic protein family. As shown in Fig. 3A and B, SOX4 downregulation markedly inhibited the expression of $\mathrm{Bcl}-2$ and survivin in the $\mathrm{A} 2058(\mathrm{P}<0.05, \mathrm{P}<0.01$, 
A
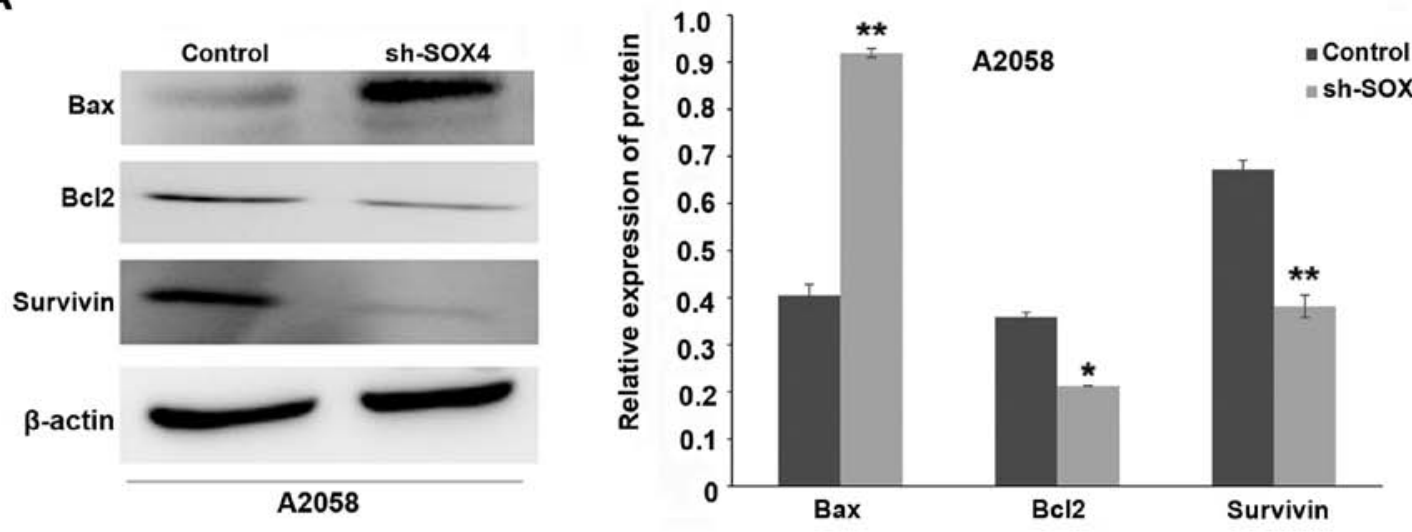

B
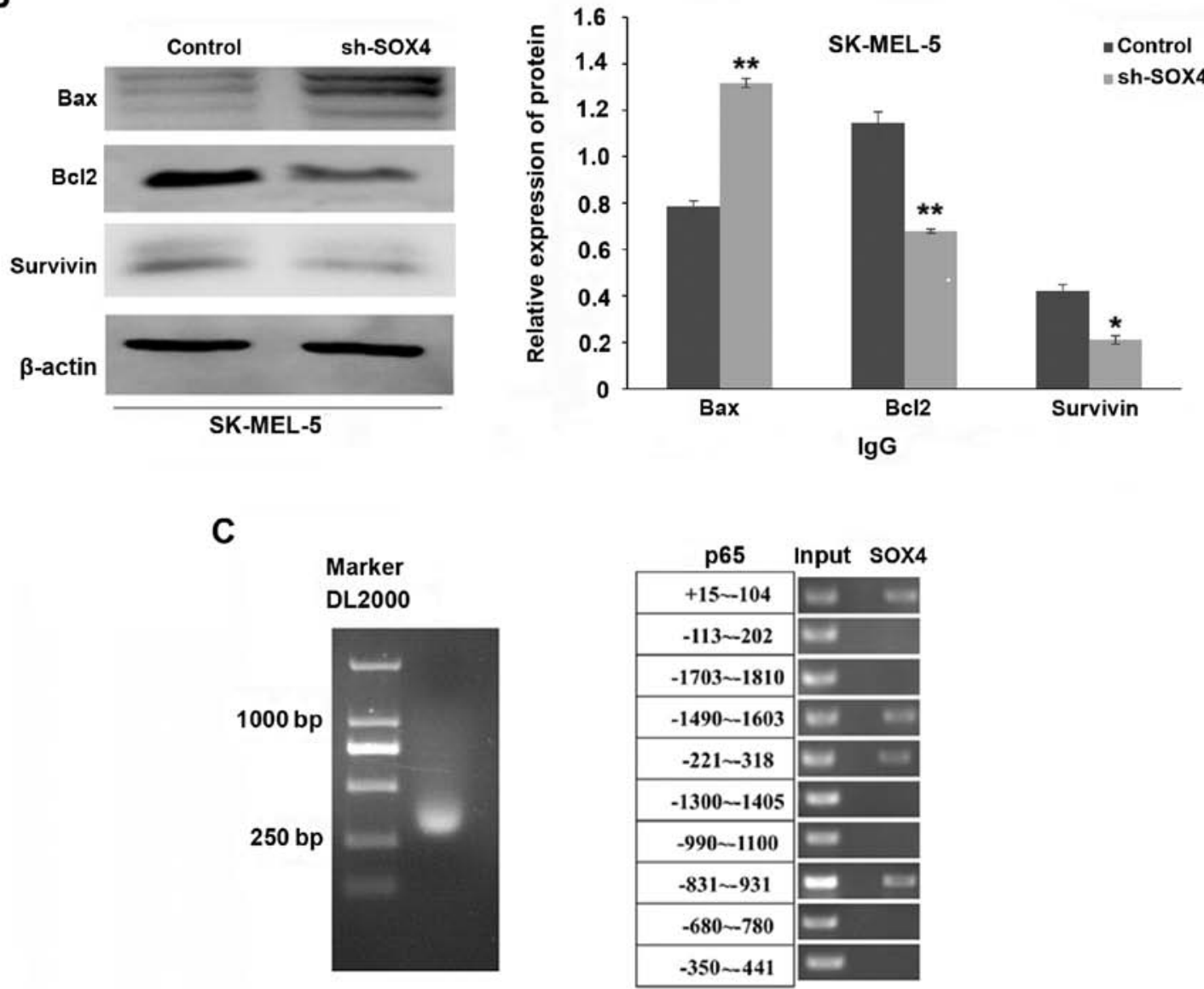

Figure 3. SOX4 downregulation decreased the expression of Bcl-2 and survivin, and increased the expression of Bax; meanwhile, SOX4 was able to bind to the promoter region of $\mathrm{p} 65$. Western blot analysis of Bax, Bcl-2 and survivin proteins in (A) A2058 and (B) SK-MEL-5 cell lines. (C) CHIP-PCR assays were performed with A2058 cells. Chromatin fragments were pulled down with anti-SOX4, using IgG as a control. Semi-quantitative PCRs were performed using specific p65 promoter primers. The assay was repeated twice. ${ }^{*} \mathrm{P}<0.05,{ }^{* *} \mathrm{P}<0.01$ indicate statistical significance. sh-SOX4 represents SOX4 shRNA.

respectively) and SK-MEL-5 ( $\mathrm{P}<0.01, \mathrm{P}<0.05$, respectively) cells, while the expression of Bax was increased $(\mathrm{P}<0.01)$. To determine whether SOX 4 could bind to the promoter region of p65, a CHIP-PCR assay was performed. As shown in Fig. 3C, SOX4 bound to the p65 promoter region at the following positions: +15 to $-104,-1490$ to $-1603,-221$ to -318 and -831 to $-931 \mathrm{bp}$.

p65 overexpression partially reverses SOX4 downregulationinduced apoptosis. As shown in Fig. 4A and B, the expression of p65 mRNA and protein was significantly increased in the p65-overexpressing and SOX4-knockdown melanoma cells, compared to SOX4-knockdown alone cells $(\mathrm{P}<0.01)$. As demonstrated in Fig. 4C and E, p65 overexpression partially reversed SOX4 downregulation-induced decreases in cell proliferation and increases in apoptosis $(\mathrm{P}<0.01, \mathrm{P}<0.05)$. The decreases in pro-PARP and survivin were also partially reversed in p65-overexpressing and SOX4-knockdown melanoma cells, compared to the SOX4-knockdown alone cells (Fig. 4D). 
A

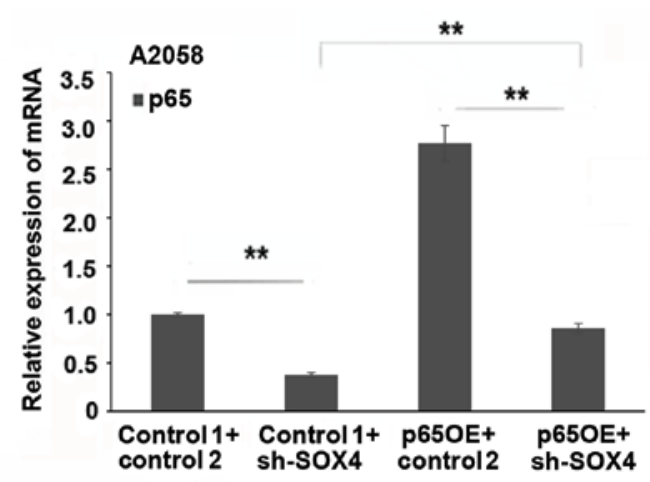

C

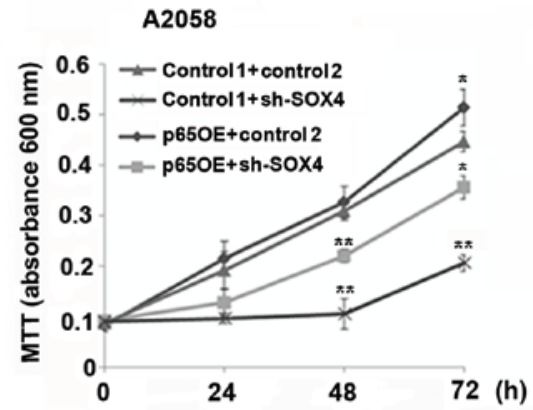

E

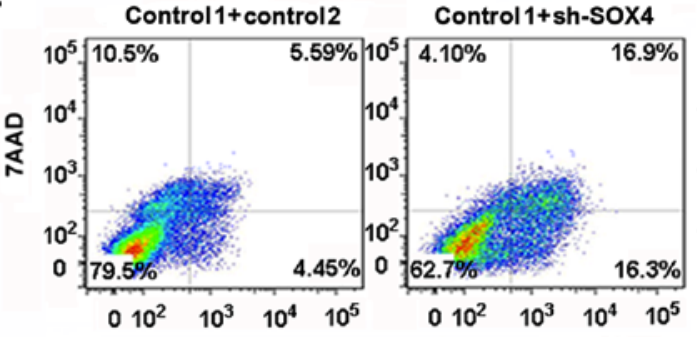

B

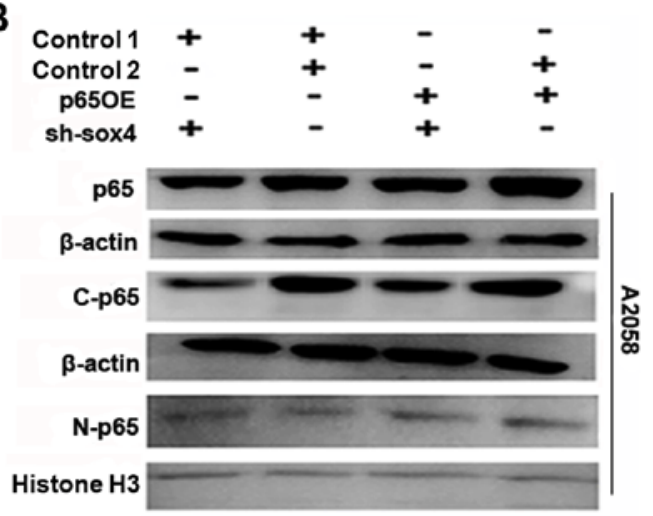

D

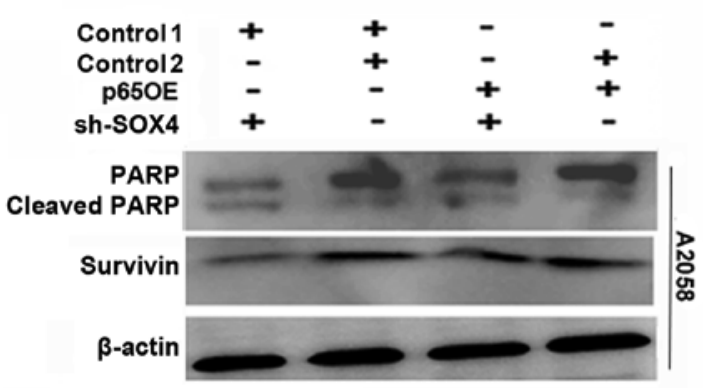

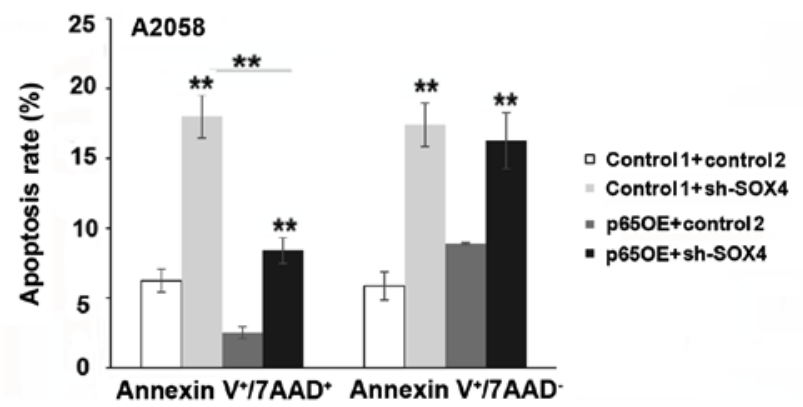

Figure 4. p65 overexpression partially reverses SOX4 downregulation-induced apoptosis. Melanoma A2058 cells were co-transfected with p65-overexpressing and SOX4 shRNA lentiviruses for $72 \mathrm{~h}$. (A) Real-time PCR assay for p65 mRNA. (B) Western blot analysis for p65. (C) Cell proliferation was determined by MTT assay after transfection for 24, 48 and $72 \mathrm{~h}$. Data are shown as the mean \pm standard deviation. (D) Western blot analysis of PARP, cleaved-PARP and survivin. (E) Apoptosis analysis. The cells were stained with Annexin V/7AAD and then analyzed by flow cytometry. Each experiment was performed in triplicate. "P $<0.05,{ }^{* *} \mathrm{P}<0.01$ indicate significance. p65-OE represents p65 overexpression. Control 1 represents p65-OE vector control. sh-SOX4 represents SOX4 shRNA. Control 2 represents sh-SOX4 vector control. N-p65 represents p65 in nuclear protein; C-p65 represents p65 in cytoplasmic protein.

\section{Discussion}

Several studies have demonstrated that SOX4 is highly expressed in nearly all of the major cancers in humans, including breast, lung, brain, prostate, colorectal, bladder and ovarian cancers, which indicates a central role in the development of multiple tumors (14). Previous studies have demonstrated that SOX4 effectively drives cells towards apop- 
tosis $(15,16)$. In bladder carcinoma cells, the pathway through which SOX4 promotes apoptosis is still not understood. This indicated that SOX4 may induce apoptosis independently of caspase-3. Downstream target genes of SOX4 are involved in signal transduction (MAP2K5), angiogenesis (NRP2), and cell cycle arrest (PIK3R3) (10). However, other studies have reached the opposite conclusion. Zhou et al revealed that downregulation of SOX4 expression induced apoptosis in lung cancer patients through upregulation of caspase-3 expression (17). The role of SOX4 in the apoptosis of melanoma cells remains unknown. In the present study, we demonstrated that downregulation of SOX4 markedly inhibited melanoma cell proliferation and promoted cellular apoptosis.

It has been reported that SOX4 may interact with many signaling pathways, such as Wnt (8) or p53 (18), to influence cellular apoptosis. Low SOX4 expression can also facilitate peritoneal macrophage apoptosis by activating caspase-3 (19). Hur et al demonstrated that there is an important structural domain in SOX4 related to apoptosis; when the glycine in the domain is replaced by serine, apoptosis is inhibited (20). Nonetheless, the mechanisms of SOX4 inhibition-induced apoptosis in melanoma cells require further investigation.

$\mathrm{NF}-\kappa \mathrm{B}$ is one of the most important transcription factors that play a crucial role in the suppression of apoptosis, as well as the induction of cell proliferation and inflammation, which is closely associated with cancer development (21-24). $\mathrm{NF}-\kappa \mathrm{B}$ activation is involved in the inhibition of apoptosis by upregulating the expression of anti-apoptotic proteins, including $\mathrm{Bcl}-2$, Mcl-1 and survivin (25). Tao et al revealed that triptolide induced melanoma A375 apoptosis by inhibiting $\mathrm{NF}-\kappa \mathrm{B}$ signaling pathways (26). However, NF- $\kappa \mathrm{B}$ has not only been proven to suppress apoptosis, but has also been proven to induce apoptosis. Schneider et al reported that $\mathrm{NF}-\kappa \mathrm{B}$ activation promoted neuronal cell death in focal cerebral ischemia (27). In this experiment, we observed that inhibition of SOX4 downregulated the expression of NF- $\mathrm{B}$ p 65 , and $\mathrm{NF}-\kappa \mathrm{B}$ p65-targeted genes, such as Bcl-2 and survivin, were also decreased.

Apoptosis is the process of programmed cell death and plays an important role in cancer development. Apoptosis involves the balance between pro-apoptotic and anti-apoptotic proteins. Tumor cells can resist apoptosis by expressing the anti-apoptotic protein $\mathrm{Bcl}-2$, while decreasing the expression of the pro-apoptotic protein Bax (28). Survivin is a member of the IAP family that inhibits cellular apoptosis, and is expressed in human melanoma, including primary melanoma and metastatic melanoma, but not expressed in normal melanocytes (29). Survivin has been found to inhibit the activity of caspase-9 by binding to HBXIP (30). Our study demonstrated that the antiapoptotic proteins Bcl-2 and survivin were downregulated, while the pro-apoptotic proteins Bax and cleaved-PARP were upregulated, in SOX4-knockdown melanoma cells.

In order to determine whether SOX4 binds to the promoter of p65, a CHIP-PCR assay was performed. Our data revealed that SOX4 was able to bind to the p65 promoter at positions +15 to $-104,-1490$ to $-1603,-221$ to -318 and -831 to $-931 \mathrm{bp}$. However, the CHIP-PCR assay only indicated that there was a connection between SOX4 and NF- $\kappa \mathrm{B}$ p65, and it could not confirm whether the connection was direct or indirect. Further research needs be performed to confirm a direct binding event.
We also revealed that p65 overexpression partially reversed SOX4 knockdown-induced increases in apoptosis, which further suggested that inhibition of SOX4 induces melanoma cell apoptosis partially through the downregulation of NF- $\kappa \mathrm{B}$ p65 signaling.

In conclusion, we demonstrated that inhibition of SOX4 markedly induced melanoma cell apoptosis via downregulation of the $\mathrm{NF}-\kappa \mathrm{B}$ signaling pathway, which thus may serve as a novel approach for the treatment of melanoma.

\section{Acknowledgements}

Not applicable.

\section{Funding}

The present study was funded by the Fundamental Research Funds for the Central Universities (no. 1507219067), the National Natural Science Foundation of China (no. 81673917) and Shanghai Municipal Commission of Health and Family Planning (no. 201440336).

\section{Availability of data and materials}

The datasets used during the present study are available from the corresponding author upon reasonable request.

\section{Authors' contributions}

QC, HX and JFW conceived and designed the study. QC, JD, LX performed the experiments. QC and JD wrote the paper. XL and ZL analyzed the data. FGZ, JFW, JHX and QC reviewed and edited the manuscript. All authors read and approved the manuscript and agree to be accountable for all aspects of the research in ensuring that the accuracy or integrity of any part of the work are appropriately investigated and resolved.

\section{Ethics approval and consent to participate}

All experimental protocols were approved by the Institutional Review Board of the Department of Laboratory Animal Science of Fudan University (Shanghai, China).

\section{Consent for publication}

Not applicable.

\section{Competing interests}

The authors declare that they have no competing interests.

\section{References}

1. Rhodes DR, Yu J, Shanker K, Deshpande N, Varambally R, Ghosh D, Barrette T, Pandey A and Chinnaiyan AM: Large-scale meta-analysis of cancer microarray data identifies common transcriptional profiles of neoplastic transformation and progression. Proc Natl Acad Sci USA 101: 9309-9314, 2004.

2. Zhang J, Jiang H, Shao J, Mao R, Liu J, Ma Y, Fang X, Zhao N, Zheng S and Lin B: SOX4 inhibits GBM cell growth and induces G0/G1 cell cycle arrest through Akt-p53 axis. BMC Neurol 14: 207, 2014 
3. Shi S, Cao X, Gu M, You B, Shan Y and You Y: Upregulated expression of SOX4 is associated with tumor growth and metastasis in nasopharyngeal carcinoma. Dis Markers 2015: 658141, 2015

4. Liu P, Ramachandran S, Ali Seyed M, Scharer CD, Laycock N, Dalton WB, Williams H, Karanam S, Datta MW, Jaye DL, et al: Sex-determining region Y Box 4 is a transforming oncogene in human prostate cancer cells. Cancer Res 66: 4011-4019, 2006.

5. Yoon TM, Kim SA, Cho WS, Lee DH, Lee JK, Park YL, Lee KH, Lee JH, Kweon SS, Chung IJ, et al: SOX4 expression is associated with treatment failure and chemoradioresistance in oral squamous cell carcinoma. BMC Cancer 15: 888, 2015.

6. Hur W, Rhim H, Jung CK, Kim JD, Bae SH, Jang JW, Yang JM, Oh ST, Kim DG, Wang HJ, et al: SOX4 overexpression regulates the p53-mediated apoptosis in hepatocellular carcinoma: Clinical implication and functional analysis in vitro. Carcinogenesis 31 : 1298-1307, 2010.

7. Pramoonjago P, Baras AS and Moskaluk CA: Knockdown of Sox 4 expression by RNAi induces apoptosis in ACC3 cells. Oncogene 25: 5626-5639, 2006.

8. Bilir B, Kucuk O and Moreno CS: Wnt signaling blockage inhibits cell proliferation and migration, and induces apoptosis in triple-negative breast cancer cells. J Transl Med 11: 280 2013.

9. Pan X, Zhao J, Zhang WN, Li HY, Mu R, Zhou T, Zhang HY, Gong WL, Yu M, Man JH, et al: Induction of SOX4 by DNA damage is critical for p53 stabilization and function. Proc Natl Acad Sci USA 106: 3788-3793, 2009.

10. Aaboe M, Birkenkamp-Demtroder K, Wiuf C, Sørensen FB, Thykjaer T, Sauter G, Jensen KM, Dyrskjøt L and Ørntoft T: SOX4 expression in bladder carcinoma: Clinical aspects and in vitro functional characterization. Cancer Res 66: 3434-3442, 2006.

11. Li J, Zhang Z and Li G: Patient outcome prediction using multiple biomarkers in human melanoma: A clinicopathological study of 118 cases. Exp Ther Med 2: 131-135, 2011.

12. Jafarnejad SM, Wani AA, Martinka M and Li G: Prognostic significance of Sox4 expression in human cutaneous melanoma and its role in cell migration and invasion. Am J Pathol 177: 2741-2752, 2010.

13. Watanabe $M$, Umezawa $K$, Higashihara $M$ and Horie R: Combined inhibition of NF- $\mathrm{KB}$ and $\mathrm{Bcl}-2$ triggers synergistic reduction of viability and induces apoptosis in melanoma cells. Oncol Res 21: 173-180, 2013.

14. Vervoort SJ, van Boxtel R and Coffer PJ: The role of SRY-related HMG box transcription factor 4 (SOX4) in tumorigenesis and metastasis: Friend or foe? Oncogene 32: 3397-3409, 2013.

15. Ahn SG, Kim HS, Jeong SW, Kim BE, Rhim H, Shim JY, Kim JW, Lee JH and Kim IK: Sox-4 is a positive regulator of Hep3B and HepG2 cells' apoptosis induced by prostaglandin (PG) $\mathrm{A}_{2}$ and $\Delta^{12}-\mathrm{PGJ}_{2}$. Exp Mol Med 34: 243-249, 2002.
16. Ahn SG, Cho GH, Jeong SY, Rhim H, Choi JY and Kim IK: Identification of cDNAs for Sox-4, an HMG-Box protein, and a novel human homolog of yeast splicing factor SSF-1 differentially regulated during apoptosis induced by prostaglandin $\mathrm{A}_{2} / \Delta^{12}-\mathrm{PGJ}$ in Hep3B cells. Biochem Biophys Res Commun 260: 216-221, 1999.

17. Zhou Y, Wang X, Huang Y, Chen Y, Zhao G, Yao Q, Jin C, Huang Y, Liu X and Li G: Down-regulated SOX4 expression suppresses cell proliferation, metastasis and induces apoptosis in Xuanwei female lung cancer patients. J Cell Biochem 116: 1007-1018, 2015.

18. Jang SM, Kang EJ, Kim JW, Kim CH, An JH and Choi KH: Transcription factor Sox4 is required for PUMA-mediated apoptosis induced by histone deacetylase inhibitor, TSA. Biochem Biophys Res Commun 438: 445-451, 2013.

19. Weng HL and Wang MJ: Effects of microRNA-338-3p on morphine-induced apoptosis and its underlying mechanisms. Mol Med Rep 14: 2085-2092, 2016.

20. Hur EH, Hur W, Choi JY, Kim IK, Kim HY, Yoon SK and Rhim H: Functional identification of the pro-apoptotic effector domain in human Sox4. Biochem Biophys Res Commun 325: 59-67, 2004.

21. Murtas D, Piras F, Minerba L, Ugalde J, Piga M, Maxia C, Perra MT and Sirigu P: Nuclear factor- $\kappa$ B expression is predictive of overall survival in patients with cutaneous melanoma. Oncol Lett 1: 633-639, 2010.

22. Karin M, Cao Y, Greten FR and Li ZW: NF-kappaB in cancer: From innocent bystander to major culprit. Nat Rev Cancer 2: 301-310, 2002.

23. Park MH and Hong JT: Roles of NF- $\mathrm{kB}$ in cancer and inflammatory diseases and their therapeutic approaches. Cells 5: 15, 2016.

24. Savva CG, Totokotsopoulos S, Nicolaou KC, Neophytou CM and Constantinou AI: Selective activation of TNFR1 and NF- $\kappa B$ inhibition by a novel biyouyanagin analogue promotes apoptosis in acute leukemia cells. BMC Cancer 16: 279, 2016.

25. Pahl HL: Activators and target genes of Rel/NF-kappaB transcription factors. Oncogene 18: 6853-6866, 1999.

26. Tao Y, Zhang ML, Ma PC, Sun JF, Zhou WQ, Cao YP and Li LJ: Triptolide inhibits proliferation and induces apoptosis of human melanoma A375 cells. Asian Pac J Cancer Prev 13: 1611-1615, 2012.

27. Schneider A, Martin-Villalba A, Weih F, Vogel J, Wirth T and Schwaninger M: NF-kappaB is activated and promotes cell death in focal cerebral ischemia. Nat Med 5: 554-559, 1999.

28. Li F and Ling X: Survivin study: An update of "what is the next wave'? J Cell Physiol 208: 476-486, 2006.

29. Grossman D, McNiff JM, Li F and Altieri DC: Expression and targeting of the apoptosis inhibitor, survivin, in human melanoma. J Invest Dermatol 113: 1076-1081, 1999.

30. Marusawa H, Matsuzawa S, Welsh K, Zou H, Armstrong R, Tamm I and Reed JC: HBXIP functions as a cofactor of survivin in apoptosis suppression. EMBO J 22: 2729-2740, 2003. 